\title{
Serviços ambientais e \\ o Delta do Jacuí
}

\begin{tabular}{lr}
\hline Eliézer Silveira Munhoz & $\begin{array}{l}\text { Universidade Estadual do Rio Grande do } \\
\text { Sul, Unidade Universitária em Tapes. }\end{array}$ \\
Jeissiquele Conter Christmann & $\begin{array}{r}\text { Tapes, RS, Brasil. } \\
\text { E-mails: eliezer-munhoz@uergs.edu.br } \\
\text { jeissiquele-christmann@uergs.edu.br } \\
\text { júlia Bolog-lima@uergs.edu.br }\end{array}$ \\
Daniela Cristina Hass Limberger & daniela-limberger@uergs.edu.br \\
\hline
\end{tabular}

Recebido em: 14 mar. 2017. Revisado: 21 mar. 2017. Aceito: 02 abr. 2017.

DOI: http://dx.doi.org/10.21674/2448-0479.34.704-710

\section{Resumo}

Serviços ambientais são os benefícios que as pessoas obtêm dos ecossistemas, cujas características fundamentais são as conexões mantidas com as funções, processos e estruturas dos ecossistemas que os originam. O Delta do Jacuí é um conjunto hidrográfico, que forma o arquipélago composto por 30 ilhas e áreas continentais, canais, pântanos e charcos do Rio Grande do Sul, vizinho de Porto Alegre, cumpre importantes funções ecológicas que melhoram a vida na cidade.

Palavras-chave: Serviços Ambientais. Ecossistema. Desta do Jacuí. 


\section{Introdução}

Bens e serviços ecossistêmicos ou serviços ambientais são os benefícios que as pessoas obtêm dos ecossistemas. Os serviços ecossistêmicos, podem ser classificados de maneira semelhante às funções ecossistêmicas como: serviços de provisão, serviços de regulação, serviços culturais e serviços de suporte (ANDREDE; ROMEIRO, 2009). O conceito tem implícita a ideia de valor econômico ou valor de uso e dos benefícios ambientais resultantes de intervenções humanas na dinâmica dos ecossistemas. Condições e processos provenientes dos ecossistemas naturais e das espécies que os compõem que sustentam e mantêm a vida humana; benefícios para populações humanas que derivam, direta ou indiretamente, das funções dos ecossistemas; processos naturais que garantem a sobrevivência das espécies no planeta e têm a capacidade de prover bens e serviços que satisfazem necessidades humanas; não são os benefícios, mas componentes da natureza diretamente aproveitados, consumidos ou usufruídos para o bem-estar humano; as contribuições dos ecossistemas que afetam diretamente ou indiretamente o bem-estar humano. A característica fundamental dos serviços ambientais são as conexões mantidas com as funções, processos e estruturas do ecossistema que os originam (EMBRAPA, 2015).

O Delta do Jacuí é um conjunto hidrográfico, que forma o arquipélago composto por 29 ilhas e áreas continentais, canais, pântanos e charcos do Rio Grande do Sul, que se formam a partir do encontro dos rios Gravataí, Sinos, Caí e Jacuí, cujas águas formam o lago Guaíba e seguem para a Laguna dos Patos. Localiza-se nos municípios de Porto Alegre, Canoas, Nova Santa Rita, 
Triunfo, Charqueadas e Eldorado do Sul, totalizando uma área de 14.242,05 hectares. Atualmente é protegido por duas unidades de conservação ambiental: o Parque Estadual Delta do Jacuí e a Área de Proteção Ambiental Delta do Jacuí.

A natureza foi generosa no encontro dos cinco rios que formam o Lago Guaíba. A região abriga dezenas de ilhas e uma diversidade de espécies de fauna e flora cuja importância foi reconhecida por decreto estadual há 40 anos. O Parque Estadual Delta do Jacuí, uma unidade de conservação de uso restrito foi criado com o objetivo principal de preservação dos ecossistemas da região.

Este estudo busca reunir informações referentes ao funcionamento ecossistêmico do Delta do Jacuí, destacar sua importância para a região onde esta inserida e caracterizar seus componentes.

\section{Metodologia}

O estudo originou-se da disciplina de economia e meio ambiente inserida na grade curricular do curso de Bacharelado em Gestão Ambiental. Para elaborar o artigo foi necessário a realização pesquisas na bibliografia que abarcassem o tema serviços ambientais, juntamente com o conhecimento da legislação estadual, decreto onde foi instituído o parque e uma série de pesquisas sobre o funcionamento do mesmo. 


\section{Resultados e Discussão}

O Parque Estadual do Delta do Jacuí foi criado em 1976 pelo Decreto $n^{\circ} 24.385$ de 14 de Janeiro (RIO GRANDE DO SUL, 1976). Inicialmente o Parque era composto por dezenove ilhas de vários tamanhos, constituídas a partir de deposição sedimentária, e por porções continentais. Em 1979, através do Decreto $n^{\circ} 28.161$ de 16 de Janeiro, são integradas ao Parque Estadual do Delta do Jacuí outras dez ilhas e áreas marginais. Atualmente o Parque é composto por 29 ilhas e áreas continentais marginais, com uma área total de 14.242,05ha hectares (LEI No 12.371, DE 11 DE NOVEMBRO DE 2005), de terras emersas continentais e as vinte e nove ilhas, sendo algumas delas, pequenas ilhas em formação ainda sem denominação, situando-se entre as coordenadas geográficas de $25^{\circ} 53^{\prime}$ e $30^{\circ} 03^{\prime}$ de latitude sul e $51^{\circ} 28^{\prime}$ e $51^{\circ} 13^{\prime}$ de longitude oeste, distribuindo-se pelos municípios de Porto Alegre, Canoas, Triunfo, Nova Santa Rita e Eldorado do Sul (TORRES; BELLOLI, 2004).

O Delta do Jacuí é uma das áreas úmidas mais importantes do Estado, suas florestas e banhados abrigam juncos, aguapés, sarandis, ingazeiros e algumas espécies protegidas da flora gaúcha, como a corticeira-do-banhado e a figueira. A fauna também é rica: na região são encontrados $1 / 3$ das espécies de anfíbios do Rio Grande do Sul. A mesma proporção é válida para os peixes de água doce ocorrentes no Estado. A região serve de refúgio ainda para mais de 190 espécies de aves (SEMA, 2006).

Nos ecossistemas ocorrem diversos processos naturais, que resultam das complexas interações entre os seus componentes bióticos (organismos vivos) e abióticos (componentes físicos e químicos) por meio das forças universais de matéria e energia. Esses 
processos naturais garantem a sobrevivência das espécies no planeta e têm a capacidade de prover bens e serviços que satisfazem necessidades humanas direta ou indiretamente (MMA, 2011).

O Parque não é apenas um reduto de exuberante natureza. Vizinho de Porto Alegre, cumpre importantes funções ecológicas que melhoram a vida na cidade. As ilhas e os banhados do Delta evitam o rápido escoamento das águas dos rios. Em períodos de cheias, isto ajuda na contenção de enchentes. A vegetação de macrófitas aquáticos funciona como filtro, retendo poluentes que chegariam ao Guaíba, de onde é tirada a água para abastecimento da cidade (SEMA, 2006).

As matas ciliares da área do Delta funcionam como filtro ambiental, retendo poluentes e sedimentos que chegariam aos cursos d'água, sendo fundamentais para o equilíbrio dos ecossistemas aquáticos (SEGANFREDO et al, 2008). Além disso, o Delta se enquadra em todas as classificações de serviços ambientais acima citados, diversificando a forma de se olhar para o ecossistema, e ampliando as oportunidades de preservação do mesmo.

\section{Considerações finais}

É perceptível a importância do Parque Estadual do Delta do Jacuí quando se trata do tema serviços ambientais, e é relevante que se façam estudos aprofundados na região visando ampliar o conhecimento da dinâmica local, até mesmo para propor mecanismos de PSA - Pagamento por Serviços Ambientais, o que auxilia na preservação do ecossistema. 


\section{Referências}

ANDRADE, D. C; ROMEIRO, A. R. SERVIÇOS ECOSSISTÊMICOS E SUA IMPORTÂNCIA PARA O SISTEMA ECONÔMICO E $O$ BEM-ESTAR HUMANO. IE/UNICAMP, Campinas, n. 155, fev. 2009.

EMBRAPA. SERVIÇOS AMBIENTAIS EM SISTEMAS AGRÍCOLAS E FLORESTAIS DO BIOMA MATA ATLÂNTICA. Brasília, DF. 2015.

MMA, Ministério do Meio Ambiente. PAGAMENTO POR SERVIÇOS AMBIENTAIS NA MATA ATLÂNTICA LIÇÕES APRENDIDAS E DESAFIOS. Brasília - DF. 2011.

RIO GRANDE DO SUL. DECRETO N 24.385, DE 14 DE JANEIRO DE 1976. Cria o Parque Estadual do Delta do Jacuí, constitui em Reserva Biológica as llhas das Pombas e da Pólvora e dá outras providências. Disponível em: < http://www.al.rs.gov.br/legis/M010/M0100099.ASP?Hid_Tipo=TEXT O\&Hid_TodasNormas $=32787 \&$ hTexto $=\& H i d \_I D N o r m a=32787>$ Acesso em: 29 de nov. de 2016.

RIO GRANDE DO SUL. DECRETO N 28.161, DE 16 DE JANEIRO DE 1979. Altera o Decreto $n^{\circ} 24.385$, de 14 de janeiro de 1976, amplia a área do Parque Estadual Delta do Jacuí, e dá outras providências. Disponível em:

http://www.icmbio.gov.br/cepsul/images/stories/legislacao/Decretos/ 1979/dec_28161_1979_parqueestadualdeltajacui_altr_dec_24385_1 976.pdf> Acesso em: 29 de nov. de 2016.

RIO GRANDE DO SUL. LEI N 12.371, DE 11 DE NOVEMBRO DE 2005. Cria a Área de Proteção Ambiental - APA - Estadual Delta do Jacuí e o Parque Estadual Delta do Jacuí e dá outras providências.

Disponível em:

http://www.legislacao.sefaz.rs.gov.br/Site/Document.aspx?inpKey=1 07942\&inpCodDispositive=\&inpDsKeywords $=>$ Acesso em: 18 de nov. 2016. 
SEGANFREDO, F. S. S. et al. FISCALIZAÇÃO AMBIENTAL NO PARQUE ESTADUAL DELTA DO JACUÍ - RS. In: Ambiência: Guarapuava, PR - v.4 n.1 p.119-127 Jan./Abr. 2008. Disponível em: $<$ http://revistas.unicentro.br/index.php/ambiencia/article/viewFile/293/ 1891>. Acesso em: 18 de nov. 2016.

SEMA. Secretaria do Ambiente e Desenvolvimento Sustentável. PARQUE DELTA DO JACUÍ COMEMORA 30 ANOS DE PRESERVAÇÃO. $2006 . \quad$ Disponível em: <http://www.sema.rs.gov.br/conteudo.asp?cod_menu=4\&cod_conte udo $=3877>$. Acesso em: 18 de nov. 2016.

TORRES, E. M; BELLOLI, R. O DELTA DO JACUÍ. Unilasalle: Canoas, jul. 2004. Disponível em: < http://www.labin.unilasalle.edu.br/infoedu/siteinfoedu1_03/webs2_qui nta04/euric/O\%20Delta\%20do\%20Jacu\%DD.pdf> Acesso em: 18 de nov. 2016. 